\title{
Comparative study on the effect of Gliclazide and two Antidiabetic plants used in Folk Medicine on Albino Rat's fetuses
}

\author{
Ibrahim G. Ibrahim*, Boshra El-Salkh**, Nagwa Shawki**, \\ Shadia M. *** and Hala M. Abou El-Fotouh*** \\ * Zoology department, Faculty of Science, Al - Azhar University for boys. \\ ** Zoology department, Faculty of Science, Al - Azhar University for girls. \\ *** Faculty of Pharmacy Cairo University.
}

\begin{abstract}
The present study was designed to assess the adverse effects of gliclazide and two antidiabetic plants extracts on $15 \& 18$ days fetuses of albino rat (Rattus norvegicus). The two antidiabetic plants extracts were aquatic extract of Aremisia herba alba (shih-balady) and alcoholic extract of Salix babylonica L. leaves (Om-Ashoor) which is known by salicin. The doses used were $4 \mathrm{mg} / \mathrm{kg}$ (Katsumata, and kastumata 1990) for the gliclazide drug (diamicron), $450 \mathrm{mg} / \mathrm{kg}$ for Artemisia herba alba (Al-Waili, 1986) and $1.5 \mathrm{gm} / \mathrm{kg}$ for salicin. Pregnant rats were given orally the applied does level every other day from the onset of gestation till the $15^{\text {th }}$ or to the $18^{\text {th }}$ day. The pregnant rats were divided into control group (G1); diabetic pregnant female rats (G2); Artemisia treated group (G3); salicin treated group (G4) and glicalzide treated group (G5). Fetuses showed diminution of size. Crown-rump lentght while the number of embryos increased in case of salicin treatment and decreased in case of gliclazide treatment due to increased resorption rate.

The endoskeleton system of fetuses obtained from pregnant diabetic mothers (G2) showed normal ossification in all fetuses with enlarged skeleton.

Some fetuses of Artemisia treated group showed major enoskeletal anomalies in the from of incomplete ossification of the skull bones, or missing in some skull bones, and also missing of caudal vertebrae.

Salicin treated group fetuses showed lack in ossification of the nasal, frontal and complete absence of parietal bone. While gliclazide treated group fetuses showed moderate ossification of nasal and frontal bones. On the other hand parietal bone exhibited complete missing.
\end{abstract}

\section{Introduction}

Traditional antidiabetic plants might provide a useful source of new oral hypolglycemic compounds for the development as pharmaceutical entities or as simple dietary adjuncts for existing therapies (Marles, and Farnsworth 1995).

The present study concerned with the effect of two hypoglycemic plants used in folk medicine and gliclazide (diamicron) as a urea sulphony drug. The two antidiabetic plant extracts were aquatic extract of Artemisia herba alba sand alcoholic extracts of Salix babylonica L. leaves (OmAshoor) which known by salicin.
Soler et al. (1976) stated that the congenital malformations in infants of diabetic mothers are three to four times higher than in the normal populations of Birmingham. The malformations were fatal and ccounted for 26 percent of the perinatal mortality. Central nervous system, cardiovascular and skeletal abnormalities were equally common and there was a high incidence of anencephalus, Spina bifida, transposition of the great vessels and sacral dysgenesis.

Temesio and poses, (1977) noticed the congenital malformation in diabetic 
offsprings in relation to age of mothers, class of maternal diabetes, maternal angipathy, treatment and metabolic control.

Goodman and Gilman, (1980), reported that, there are two major types of oral hypoglycemic drugs, the sulphonylurea and biguanides.

Ganda and weir (1990), reported that over the past five decades, a number of submitted sulphonylureas have widely used as hypoglycemic agents in the control of maturity through stimulating insulin secretion from B-cells or by reducing the insulin resistance that is always present in non-insulin dependent diabetes mellitus.

Azzam (1984), noticed the striking hypoglycemic effect of salicin which more or less similar to sulphonylurea drugs.

Al-waili (1986), stated that Artemisia herba alba extract might have a potent effect in reducing blood sugar and controlling diabetic symptoms.

Abdel-Moneim (1998), noticed the effect of Artemisia herba alba which more or less similar to gliclazide.

\section{Material And Methods}

The present study was carried out on 125 pregnant female rats in which 100 of them induced diabetic by aloxan injection $(120 \mathrm{mg} / \mathrm{kg}$ bwt ) (El-Fiky et al., 1997). The alloxan induced diabetic female rats were divided into 3 groups 1st group diabetic pregnant female rats treated with Artemisia herba alba, 2 nd group diabetic pregnant female rats treated with salicin, and3rd groups diabetic pregnant female rats treated with gliclazide.

The oral dose used was $450 \mathrm{mg} / \mathrm{kg}$ of Artemisia herba alba. This does is calculated by paste and Sarnes (1964), and 1.5 $\mathrm{mg} / \mathrm{kg}$ of salicin (Azzam 1984). The does was calculated by paste and Sarnes (1964) and $4 \mathrm{mg} / \mathrm{kg}$ of gliclazide (Kastumata, and kastumata 1990) as suspension.

The oral doses used were applied from the $1^{\text {st }}$ to the $15^{\text {th }}$ day or to the $18^{\text {th }}$ day. On the $15^{\text {th }}$ day and the $18^{\text {th }}$ day the pregnant female rats were sacrified by decapitation and the obtained fetuses were fixed in neutral formol. While fetuses chosen for Alizarinred stain (Sedra, 1950) were transferred to $70 \%$ alcohol.

Morphological studies:

In fetuses:

a. Number of embryos.

The number of fetuses present in the two horns of the uteri obtained from the different groups under investigation was recorded.

\section{b. Body weight of fetuses.}

The body weight of fetuses was performed after dissection using a sensitive balance.

\section{c. Average body length.}

The body length of fetuses was measured from the beak of the skull to the end of the tail using a compass filament.

\section{d. Malformation of fetuses.}

Fetuses from all groups were observed for any apparent gross anomalies.

\section{e. Endoskeletal studies.}

Skeletal system was examined for the presence or absence of ossification centers after staining with Alizarin red method according to Sedra (1950).

\section{Results}

1. Morphological studies:

A. In pregnant Female rats:

- Weights of pregnant female rats.

From table (1) and figures ( $3 \& 4)$, it is clear that control and experimental animals showed progressive increase in body weight with the pregnancy and lapse of time. The increase in body weight of control amounted an increment on the $7^{\text {th }}$, $14^{\text {th }}$ and $18^{\text {th }}$ day reached $7.29 \%, 14.60 \%$ and $20.62 \%$ respectively. Among experimental groups, however the gain in body weight level through $7^{\text {th }}, 14^{\text {th }}$ the and $18^{\text {th }}$ day was more than control in alloxan (diabetic) and Artemisia groups (G2 \& G3) and reduced in salicin and gliclazide group, (G4 \& G5).

Diabetic female rats $(\mathrm{G} 2)$ recorded a gradual increase in average weight reached $36.26 \%$ on day 18 , a gain of $15.64 \%$ more than control. Artemisia treated group (G3) amounted $21.35 \%$ at the end of experiment on the day 18, again more by only 0.73 from control.

The mean body weight of diabetic pregnant rats treated with salicin (G4) was 
$11.19 \%$ on day 18 . It was $8.43 \%$ less than control.

In the diabetic pregnant female rats treated with gliclazide, the gain in body weight throughout the experiment reached $6.06 \%$ on day 18 such gain was less by $14.56 \%$ from the control.

\section{B. In fetuses:}

\section{Number of fetuses:}

The number of embryos shown in table (2) and graphically presented in figure (5). Data indicate a significant increase in number of embryos in Artemisia and salicin groups in the right horn respectively. While in case of Alloxan and gliclazide groups, there was a significant decrease in both right and left horns on the day 18.

In alloxan group (G2) total number of embryos recorded 7.385 with percentage of change $23.231 \%$ less than control due to resorbed embryos in the left horn where it recorded 3.462 with standard deviation 0.66 from control as shown in table 2 and figure 6.

Artemisia and salicin groups (G3 \& G4) showed a significant increment in number of embryos where they recorded on 18 day 9.695 and 12.432 with percentage of change $41.443 \%$ and $42.13 \%$ respectively.

This change may due to an increament in number of embryos of the left and right horns where they recorded 6.615 in left horn and 7.46 in right horn with standard deviation 0.242 and 0.76 respectively (Table 2 \& Fig. 6).

Gliclazide group (G5) recorded 6.692 as total number of embryos with a percentage of change $41.125 \%$ and a significant decrease in number of embryos in the left horn where it recorded 2.692 with standard error 0.262 (Table $2 \&$ Fig. 6).

Plates (I, II, III \& IV) showed the shapes of isolated uteri from experimental and control groups on the $15^{\text {th }}$ and $18^{\text {th }}$ day of gestation, plates I \& III illustrate the two horns of the uterus of control pregnant rats, there is an equal distribution of embryos in both horns without signs of resorption or other abnormalities. On the other hand uteri taken from treated rats, the uterine horns appear to be unequal in distribution of implantation sites and manifest remarkable reduction in their size and length as well as sign of resorption (Plates, I, II, III \& IV).

In the second experimental group treated with alloxan before pregnancy and sacrified on day 15 and 18 of gestation all cases showed one resorbed fetus in the whole uterus (Plate II \& III).

The third group (G3) treated with Artemisia showed a reduction in number of embryos in one horn of uterus than the other (Plate I \& III).

The uteri of rats obtained from the fourth experimental group treated with salicin (Plates I \& IV) showed a decrease in number of embryos from one horn than the other. The fifth experimental group treated with therapeutic doses from gliclazide showed on the 15 and 18 days more resorbed sites, plates (II \& IV).

\section{Body weight of fetuses:}

Table (3) and Figure (6) show a comparative study of the mean body weights of experimental litters and their control fetuses from diabetic female rats (G2) and diabetic female rats treated with Artemisia herba alba (G3) which showed a significant increase in the level of body weight when compared with control (Fig. 6). While fetuses from diabetic mothers treated with salicin (G4) and treated swith glicazide (G5) showed growth retardation than control (Fig. 6).

Table (3) declared the increase in body weight of fetuses belonging to diabetic pregnant female rats (G2), reached $28.2 \%$ and $14.07 \%$ more than control on days $15 \& 18$ respectively.

The percentage of body weight of fetuses obtained from diabetic pregnant female rats treated with Artemisia herba alba (G3) was $29.48 \%$ and $\mathrm{s} 4.48 \%$ more than the control on days $15 \& 18$ respectively.

In the salicin and gliclazide treated groups a highly significant decrease in body weight was recorded. The decrement reached $30.7 \%$ and $15.15 \%$ in salicin group (G4) on day $15 \& 18$ respectively while in gliclazide group (G2) it reached-37.18\% and $49.631 \%$ on 15 day \& 18 respectively.

From table (3) and figure (6) it is clear that there is a highly significant increase in the mean embryos weight from diabetic 
females relative to control, the maximum body weights were recorded in alloxan group (G2) followed by Artemisia group (G3). Also a highly significant decrease in the mean embryo weight from diabetic pregnant rats treated with salicin (G4) followed by gliclazide group (G5) fetuses. This indicates a marked disturbance in body weights.

\section{Average body length of fetuses (crown} - rump length) :

Data obtained from body lengths of treated and control fetuses are shown in table (4) and graphically represented in figure (7).

From table (4) and graph (7) the mean values of body lengths of litters from alloxan ad Artemisia (G2 \& G3) are 2.3 and 2.02 with standard error 0.033 and 0.039 on day 15 while on day 18 , it recorded 7.892 for alloxan and 6.909 for Artemisia with standard error 0.0655 and 0.076 respectively. Salicin and gliclazide groups (G4 \& G5) showed a significant decrease in body length on $15^{\text {th }}$ and $18^{\text {th }}$ days. On day 15 the average mean recorded $1.51 \& 0.82$ and on day 18 it recorded $4.972 \& 2.246$ respectively, with standard error 0.021 for salicin (G3) and 0.049 for gliclazide (G5) on day 15 and $0.067 \& 0.082$ on day respectively.

\section{Percentage of resorption:}

From table (5) individuals of the control, salicin and Artemisia showed no resorption in maternal uteri while the percentage of resorption in diabetic and gliclazide groups are also given in table (5). Diabetic pregnant female rats (G2) showed low percentage of resorption when compared with gliclazide group (G5) where it reached 0.53 when compared with control.

The gliclazide group recorded high percentage of resorbed embryos where it reached 3.538 on day 18 with standard deviation 0.877 .

\section{Malformation of fetuses:}

In the present study different types of malformation of fetuses obtained from diabetic mothers without treatment or diabetic mothers with different treatments on the $15^{\text {th }} \& 18^{\text {th }}$ day of gestation.
Fetuses of diabetic mothers showed on days $15 \& 18$ thickened and folded skin of gestation (photos $1 \& 5$ ).

On the other hand, the majority of fetuses of Artemisia treated group produced a variety of external malformations in fetuses taken on days $15 \& 18$, such as oedematus, skin (photos $2 \& 6$ ).

Fetuses obtained from diabetic pregnant female rats treated with salicin showed diminution in size, crown rump length; thin skin and reduced head circumference (photos $3 \& 8$ ).

Different types of malformations in fetuses obtained from diabetic pregnant rats treated with gliclazide and scarified on days $15 \& 18$ of gestation declared a high incidence sof resorption. The fetuses showed retarded size, short neck very thin skin and exencephaly (photos. $4 \& 9$ ).

\section{Endoskeletal studies:}

In the present study. The skeletal system of control and experimental fetuses were prepared on day 18 of gestation, stained with Alizarin red S, and examined by the dissecting binocular microscope. Some treated groups showed several minor skeletal variations including retardation in ossification of skull bones, ribs, vertebrae, pectoral and pelvic girdles and hind limbs, others showed normal ossification and/or enlarged skeleton.

\section{a- Gross examination of the skull:}

In the present study the skull of the fetuses 18 day showed complete ossification of the skull (photo 10). Also the diabetic mother fetuses skulls (G2) showed normal and complete ossified skulls photo10).

Moreover, Artemisia treated diabetic group showed different abnormalities in the skull structure where it exhibited three types, normal photo 11), weakly ossified with the absence of parietal and interparietal bones pho. (2-b) and absence of premaxilla, maxilla nasal, interparietal, supraoccipital, squamosal and basioccipital bones (photo. 13)

Fetuses belonging to diabetic mothers treated with salicin (photo 14) showed moderate ossified nasal and frontal bones 
will complete absence of parietal (photo. 14).

The skulls of fetuses taken from diabetic mothers treated with gliclazide showed moderate ossified nasal, and frontal bones. On the other hand parietal, interparietal and supraoccipital bones exhibited complete absence $(15-\mathrm{B})$.

\section{b- Gross examiniation of the vertebrae and ribs:}

The vertabra of animals from alloxan diabetic group (G2) were more or less similar to the control (photo. 10).

In Artemisia treated group (G3), the vertebral column appeared normal in some fetuses and completely non-ossified caudal vertebrae in others (photos. 11, 12, $13 \mathrm{~B}$ ).

Fetuses belonged to salicin treated diabetic group (G4) showed lack of ossification of lumbar and caudal vertebra (pho. 14).
Also fetuses belonged to gliclazide treated diabetic group (G5) showed lack of ossification of lumbar while sacral and caudal vertebrae are absent (photo. 15 B).

No changes could be detected in rats of all treated groups except in the group treated with Artemisia in which many fetuses appeared with short ribs, reduced number and less ossification (photo. $13 \mathrm{~B}$ ).

\section{c- Ossification of the pectoral girdle and} fore limbs:

The ossification centers of pectoral girdle, fore limbs of fetuses of control rats are shown in (photo. 10).

Bones of scapulae and clavicles of fetuses from all experimental groups, were found to be as ossified as the control, except some fetuses from Artemisia treated group, scapulae were not ossified (photo. 12).

The humerus, radius and ulna were found completely ossified in many treated fetuses (photos. 10, 11, 12, 13,14).

Table (1): Body weight (gm) commultative data of control, pregnant diabetic rats ( with Alloxan) and pregnant diabetic rats after treatment with artemisia, Salicin, and Gliclazide.

\begin{tabular}{|c|c|c|c|c|c|}
\hline \multirow{2}{*}{ Groups } & \multirow{2}{*}{$\begin{array}{l}\text { Statistical } \\
\text { Data }\end{array}$} & \multicolumn{4}{|l|}{ No. of days } \\
\hline & & Ist. & 7 th. & 14 th. & 18 th. \\
\hline \multirow{3}{*}{$\begin{array}{l}\text { Gontrol } \\
\text { (G1) }\end{array}$} & $\mathrm{M} \pm \mathrm{SE}$ & $195.96 \pm 2.48$ & $210.25 * * \pm 2.38$ & $224.57 \pm 2.21$ & $236.36^{* *} \pm 2.81$ \\
\hline & $\pm \mathrm{SD}$ & $8 . .923$ & 8.584 & 7.998 & $10.11-5$ \\
\hline & $\%$ & $\begin{array}{ll}-- \\
\end{array}$ & 7.29 & 14.60 & 20.62 \\
\hline \multirow{3}{*}{$\begin{array}{l}\text { Alloxan } \\
\text { (G2) }\end{array}$} & $\mathrm{M}+\mathrm{SE}$ & $180.29 \pm 3.72$ & $213.95 * *+3.91$ & $229.73 * *+4.00$ & $245.67 * *+4.14$ \\
\hline & $+\mathrm{SD}$ & 13.422 & 14.088 & 14.433 & 14.934 \\
\hline & $\%$ & ----- & 18.67 & 27.42 & 36.26 \\
\hline \multirow{3}{*}{$\begin{array}{l}\text { Artemisia } \\
\text { (G3) }\end{array}$} & $\mathrm{M}+\mathrm{SE}$ & $195.80 \pm 4.03$ & 221.03 & $230.83 * *+4.03$ & $237.60 * *+4.54$ \\
\hline & $\pm \underline{\mathrm{SD}}$ & 14.533 & 13.394 & 14.526 & 16.352 \\
\hline & $\%$ & $\begin{array}{ll}--- \\
\end{array}$ & 12.89 & 17.89 & 21.35 \\
\hline \multirow{3}{*}{$\begin{array}{l}\text { Salicin } \\
\text { (G4) }\end{array}$} & $\mathrm{M} \pm \mathrm{SE}$ & $187.18 \pm 4.44$ & $197.19 \pm 4.32$ & $202.98 * * \pm 3.71$ & $208.13^{* *} \pm 3.54$ \\
\hline & \pm SD & 16.016 & 15.584 & 13.366 & 12.760 \\
\hline & $\%$ & ---- & 5.35 & 8.44 & 11.19 \\
\hline \multirow{3}{*}{$\begin{array}{l}\text { Gliclazide } \\
\text { (G5) }\end{array}$} & $\mathrm{M}+\mathrm{SE}$ & $193.76 \pm 2.37$ & $199.45^{* *} \pm 2.52$ & $204.27 * *+25$ & $205.50 * *+2.69$ \\
\hline & $+\mathrm{SD}$ & 8.561 & 9.085 & 9.252 & 9.685 \\
\hline & $\%$ & ----- & 2.94 & 5.42 & 6.06 \\
\hline
\end{tabular}

$M=$ Means, $\%=$ Percentage of changes, Significant $(P<0.05)$ and highly Significant $(\mathrm{P}<0.01)$. 
Table (2): Statistical analysis of embryos body length of females, control G1), diabetic (G2) and treated groups of rats $(\mathrm{G3}, \mathrm{G4} \& \mathrm{G5})$ after 18 days of treatment.

\begin{tabular}{|c|c|c|c|c|c|c|}
\hline \multirow{2}{*}{ Groups } & & \multirow{2}{*}{$\mathrm{M}=\mathrm{S} . \mathrm{E}$. } & \multicolumn{3}{|c|}{ Measures of Individual Variability (Scatter) } & \multirow{2}{*}{$\%$} \\
\hline & & & \pm S.D & C.V.\% & Range & \\
\hline \multirow{3}{*}{$\begin{array}{l}\text { Gontrol } \\
\text { (G1) }\end{array}$} & R.H. & $4.769 \pm 0.231$ & 0.832 & 17.446 & $4.00-8.00$ & -- \\
\hline & L.H. & $4.769 \pm 0.231$ & 0.832 & 20.968 & $4.00-6.00$ & -- \\
\hline & Total & $9.538 \pm 0.231$ & 0.832 & 38.414 & $8.00-14.00$ & -- \\
\hline \multirow{3}{*}{$\begin{array}{l}\text { Alloxan } \\
\text { (G2) }\end{array}$} & R.H. & $3.923 * * \pm 0.077$ & 0.277 & 7.061 & $3.00-4.00$ & 20.969 \\
\hline & L.H. & $3.462 * * \pm 0.183$ & 0.660 & 19.064 & $3.00-5.00$ & 27.486 \\
\hline & Total & $7.385^{* *+0.13}$ & 0.462 & 26.125 & $6.00-9.00$ & 23.231 \\
\hline \multirow{3}{*}{$\begin{array}{l}\text { Artemisia } \\
\text { (G3) }\end{array}$} & R.H. & $3.08 * * \pm 0.077$ & 0.277 & 8.994 & $3.00-4.00$ & 24.510 \\
\hline & L.H. & $6.615^{* *} \pm 0.213$ & 0.242 & 11.610 & $5.00-8.00$ & 38.708 \\
\hline & Total & $9.695 * * \pm 0.1815$ & 1.647 & 42.393 & $4.50-9.50$ & 41.443 \\
\hline \multirow{3}{*}{$\begin{array}{l}\text { Salicin } \\
\text { (G4) }\end{array}$} & R.H. & $7.46^{* * \pm 0.144}$ & 0.419 & 6.957 & $7.00-8.00$ & 83.333 \\
\hline & L.H. & $4.972 * * \pm 0.067$ & 0.768 & 4.867 & $4.50-5.50$ & 4.257 \\
\hline & Total & $12.43 * * \pm 0.306$ & 0.654 & 64.99 & $6.00-13.00$ & 42.130 \\
\hline \multirow{3}{*}{$\begin{array}{l}\text { Gliclazide } \\
\text { (G5) }\end{array}$} & R.H. & $4.000 \pm 0.28$ & 1.00 & 25.00 & $2.00-5.00$ & 1.961 \\
\hline & L.H. & $2.692 \pm 0.262$ & 0.947 & 35.178 & $2.00-4.00$ & 43.552 \\
\hline & Total & $6.692 \pm 0.3745$ & 1.348 & 95.184 & $4.00-10.00$ & 41.125 \\
\hline
\end{tabular}

$M=$ Means, $\%=$ Percentage of changes, Significant $(P<0.05)$ and Highly Significant

$(P<0.01)$.

Table (3): Statistical analysis of embryos body weight of females, control G1), diabetic (G2) and treated groups of rats (G3,G4 \& G5) after 18 days of treatment.

\begin{tabular}{|c|c|c|c|c|c|c|}
\hline \multirow{2}{*}{ Groups } & \multirow{2}{*}{ After } & \multirow{2}{*}{$\mathrm{M}=\mathrm{S} . \mathrm{E}$. } & \multicolumn{3}{|c|}{ Measures of Individual Variability (Scatter) } & \multirow{2}{*}{$\begin{array}{l}\% \text { of } \\
\text { Change }\end{array}$} \\
\hline & & & \pm S.D & C.V.\% & Range & \\
\hline \multirow{2}{*}{$\begin{array}{l}\text { Gontrol } \\
\text { (G1) }\end{array}$} & 15 days & $1.56 \pm 0.022$ & 0.078 & 5.00 & $1.50-1.72$ & --- \\
\hline & 18 days & $4.612+0.060$ & 0.216 & 4.683 & $4.30-4.90$ & --- \\
\hline \multirow{2}{*}{$\begin{array}{l}\text { Alloxan } \\
\text { (G2) }\end{array}$} & 15 days & $2.00 * * \pm 0.008$ & 0.028 & 1.40 & $2.00-2.10$ & 28.205 \\
\hline & 18 days & $5.261^{* *} 0.083$ & 0.299 & 5.683 & $4.90-5.80$ & 14.072 \\
\hline \multirow{2}{*}{$\begin{array}{l}\text { Artemisia } \\
\text { (G3) }\end{array}$} & 15 days & $2.02 * * \pm 0.012$ & 0.042 & 2.079 & $2.00-2.12$ & 29.487 \\
\hline & 18 days & $4.827 *+0.097$ & 0.348 & 7.209 & $4.30-5.30$ & 4.662 \\
\hline \multirow{2}{*}{$\begin{array}{l}\text { Salicin } \\
\text { (G4) }\end{array}$} & 15 days & $1.08 * * \pm 0.023$ & 0.084 & 7.778 & $1.00-1.20$ & 30.769 \\
\hline & 18 days & $3.913 * *+0.093$ & 0.334 & 8.510 & $3.05-4.30$ & 15.156 \\
\hline \multirow{2}{*}{$\begin{array}{l}\text { Gliclazide } \\
\text { (G5) }\end{array}$} & 15 days & $0.98 * * \pm 0.008$ & 0.027 & 2.755 & $0.90-1.00$ & -37.180 \\
\hline & 18 days & $2.323^{* *} \pm 0.066$ & 0.239 & 10.288 & $2.00-2.90$ & -49.631 \\
\hline
\end{tabular}

$M=$ Means, $\%=$ Percentage of changes, $*=$ Significant $(P<0.05)$ and $* *=$ Highly

Significant $(P<0.01)$. 
Table (4): Statistical analysis of embryos body length of females, control G1), diabetic (G2) and treated groups of rats $(\mathrm{G3,G4} \&$ G5 ) after 18 days of treatment.

\begin{tabular}{|c|c|c|c|c|c|c|}
\hline \multirow{2}{*}{ Groups } & \multirow{2}{*}{ After } & \multirow{2}{*}{$\mathrm{M}=\mathrm{S} . \mathrm{E}$. } & \multicolumn{3}{|c|}{ Measures of Individual Variability (Scatter) } & \multirow{2}{*}{$\begin{array}{l}\% \text { of } \\
\text { Change }\end{array}$} \\
\hline & & & + S.D & C.V.\% & Range & \\
\hline \multirow{2}{*}{$\begin{array}{l}\text { Gontrol } \\
\text { (G1) }\end{array}$} & 15 days & $1.76 \pm 0.013$ & 0.046 & 2.614 & $1.69-1.90$ & --- \\
\hline & 18 days & $7.246 \pm 0.540$ & 0.194 & 2.677 & $6.90-7.50$ & ---- \\
\hline \multirow{2}{*}{$\begin{array}{l}\text { Alloxan } \\
\text { (G2) }\end{array}$} & 15 days & $2.3^{* *} \pm 0.033$ & 0.118 & 5.130 & $2.00-2.50$ & 30.68 \\
\hline & 18 days & $7.892 * *+0.655$ & 0.198 & 2.509 & $7.50-8.20$ & 8.915 \\
\hline \multirow{2}{*}{$\begin{array}{l}\text { Artemisia } \\
\text { (G3) }\end{array}$} & 15 days & $2.02 * * \pm 0.039$ & 0.142 & 6.698 & $2.00-2.50$ & 20.455 \\
\hline & 18 days & $6.909 * *+0.076$ & 0.273 & 3.452 & $7.45-8.30$ & -13.801 \\
\hline \multirow{2}{*}{$\begin{array}{l}\text { Salicin } \\
\text { (G4) }\end{array}$} & 15 days & $1.51 * * \pm 0.021$ & 0.076 & 5.033 & $1.30-1.60$ & -14.205 \\
\hline & 18 days & $4.972 * * \pm 0.067$ & 0.242 & 4.867 & $4.50-5.50$ & 31.383 \\
\hline \multirow{2}{*}{$\begin{array}{l}\text { Gliclazide } \\
\text { (G5) }\end{array}$} & 15 days & $0.82 * * \pm 0.049$ & 0.176 & 21.463 & $0.42-0.58$ & -53.409 \\
\hline & 18 days & $2.246^{* *} \pm 0.082$ & 0.296 & 44.524 & $1.90-2.80$ & 69.004 \\
\hline
\end{tabular}

$M=$ Means, $\%=$ Percentage of changes, $*=$ Significant $(P<0.05)$ and $* *=$ Highly Significant $(P<0.01)$.

Table (5): Statistical analysis of the resorbed embryos of control G1), diabetic (G2) and treated groups of rats $(\mathrm{G3}, \mathrm{G} 4 \&$ G5 $)$ after 18 days of treatment.

\begin{tabular}{|l|l|l|l|l|l|}
\hline \multirow{2}{*}{ Groups } & \multicolumn{6}{l}{ Measures of Individual Variability (Scatter) } \\
\cline { 2 - 6 } & Average & +S.E. & +S.D. & C.V.\% & Range \\
\hline Gontrol (G1) & 0.00 & 0.000 & 0.000 & 0.00 & --- \\
\hline Alloxan (G2) & $0.538^{* *}$ & 0.144 & 0.519 & 96.468 & $0-1$ \\
\hline Artemisia (G3) & 0.00 & 0.000 & 0.000 & 0.00 & --- \\
\hline Salicin (G4) & 0.00 & 0.000 & 0.000 & 0.00 & -- \\
\hline Gliclazide (G5) & $3.538^{* *}$ & 0.243 & 0.877 & 24.788 & $1-5$ \\
\hline
\end{tabular}

$M=$ Means, $\%=$ Percentage of changes, ${ }^{*}=$ Significant $(P<0.05)$ and $* *=$ Highly

Significant $(P<0.01)$. 

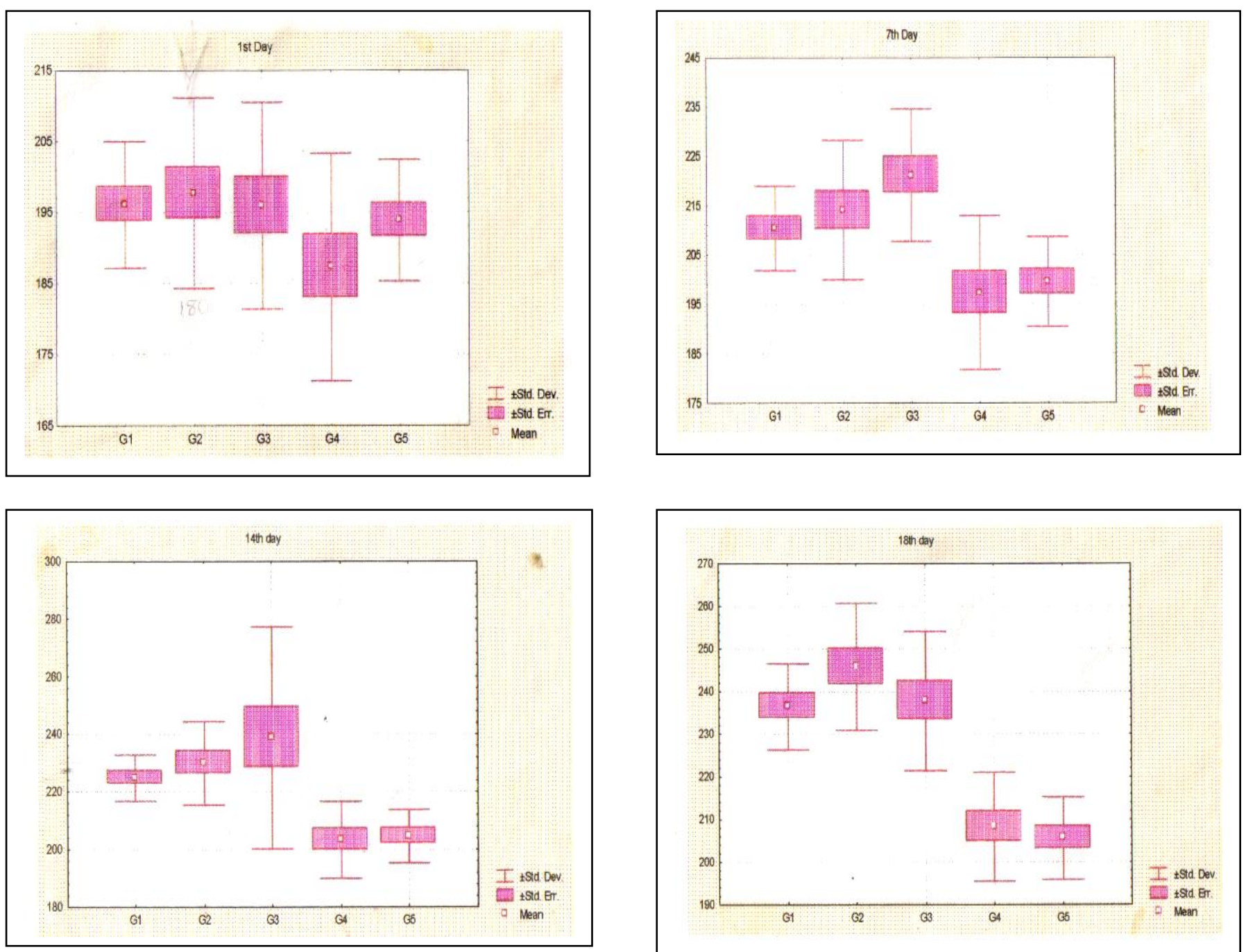

Fig.( 3) Body weight (g.) commulative data of control (G1) and pregnant diabetic rats (With Alloxan) (G2), after treat ment with Artemisia (G3), Salicin (G4) and Gliclazide (G5).

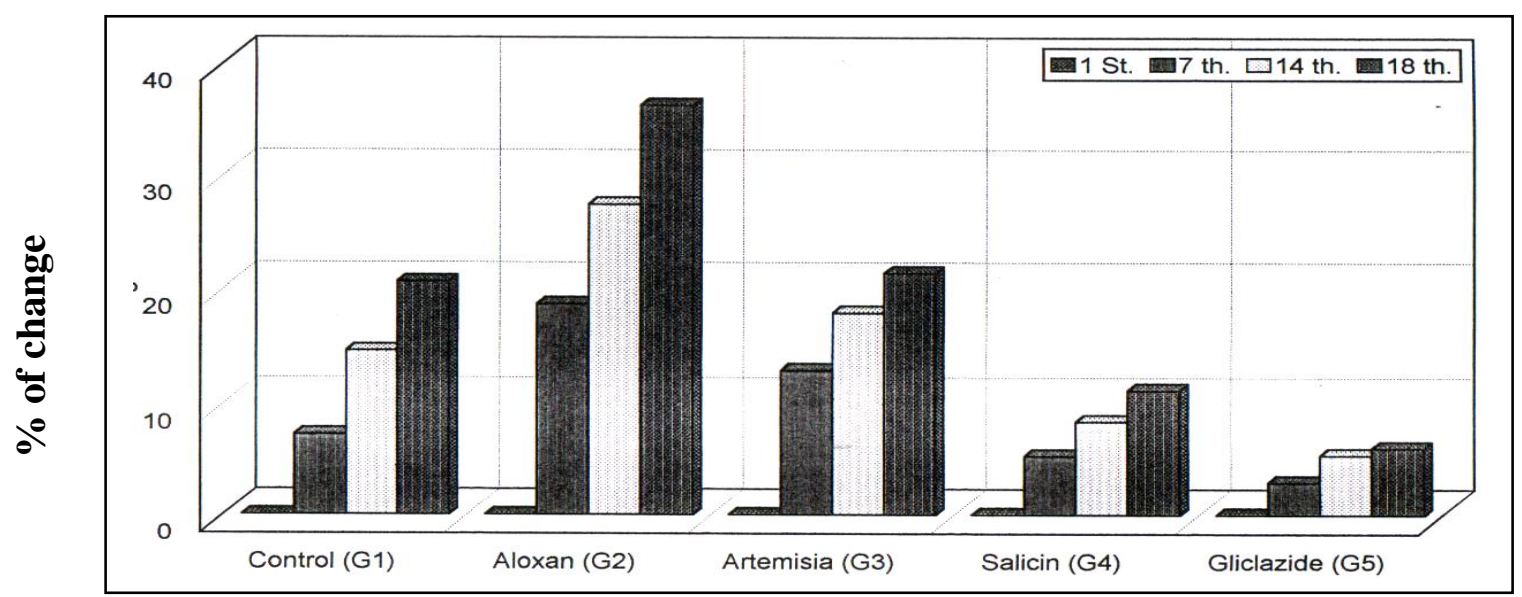

Fig.( 4 ) Percentage of change in body weight (g) commulative data of control (G1) and pregnant diabetic rats (With Alloxan) (G2), after treat ment with Artemisia (G3), Salicin (G4) and Gliclazide (G5). 


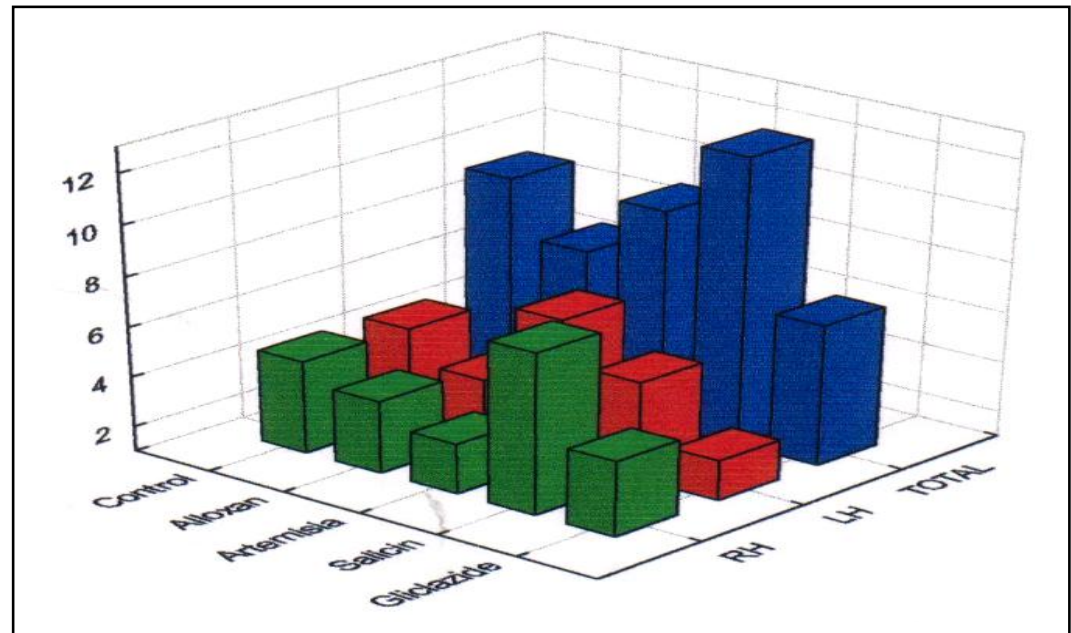

Fig.(5) Histogram illustrating the numbers of embryos in uterus of females, control, diabetic and treated groups of rates after 18 days of gestaion.

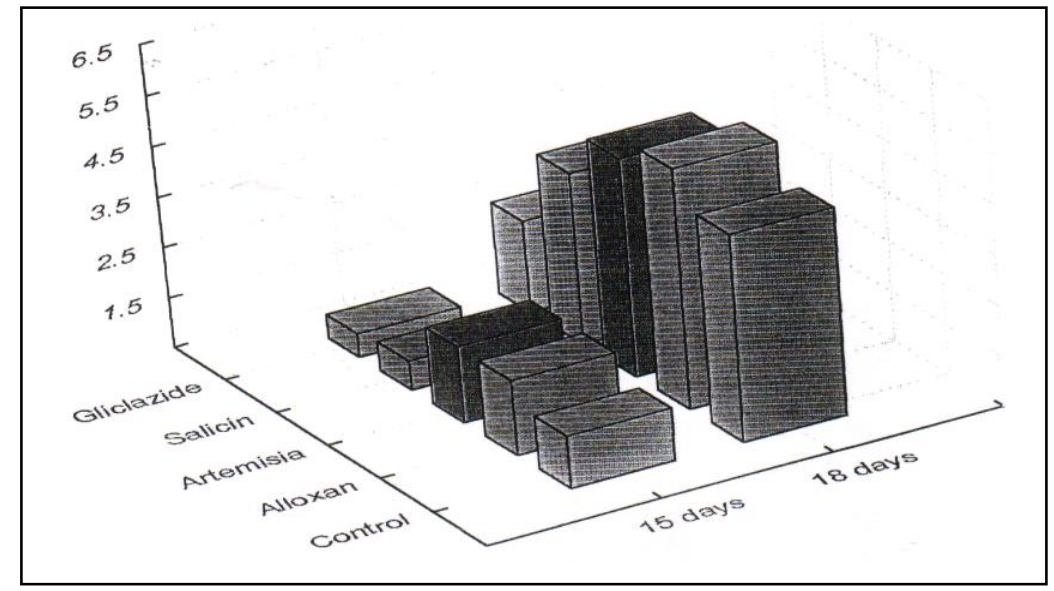

Fig.(6) Histogram illustrating the body weight of embryos in uterus of females, control, diabetic and treated groups of rates after 15 and 18 days of gestaion.

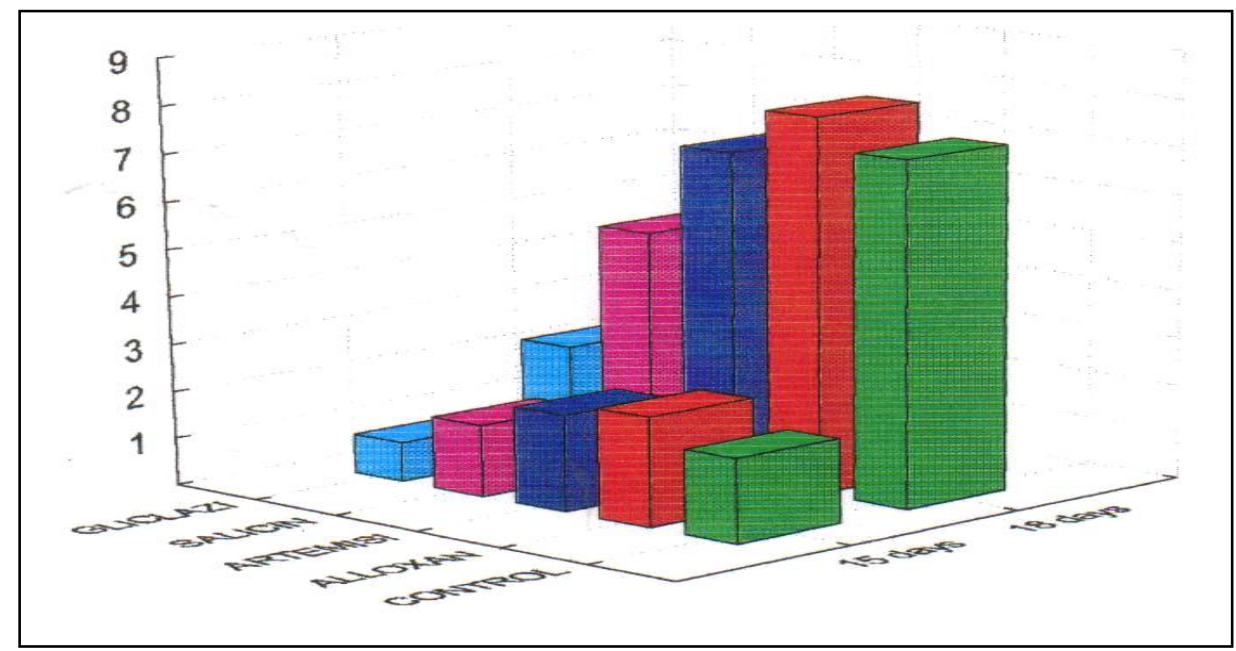

Fig.(7) Histogram illustrating the body length of embryos in uterus of females, control, diabetic and treated groups of rates after 15 and 18 days of gestaion. 

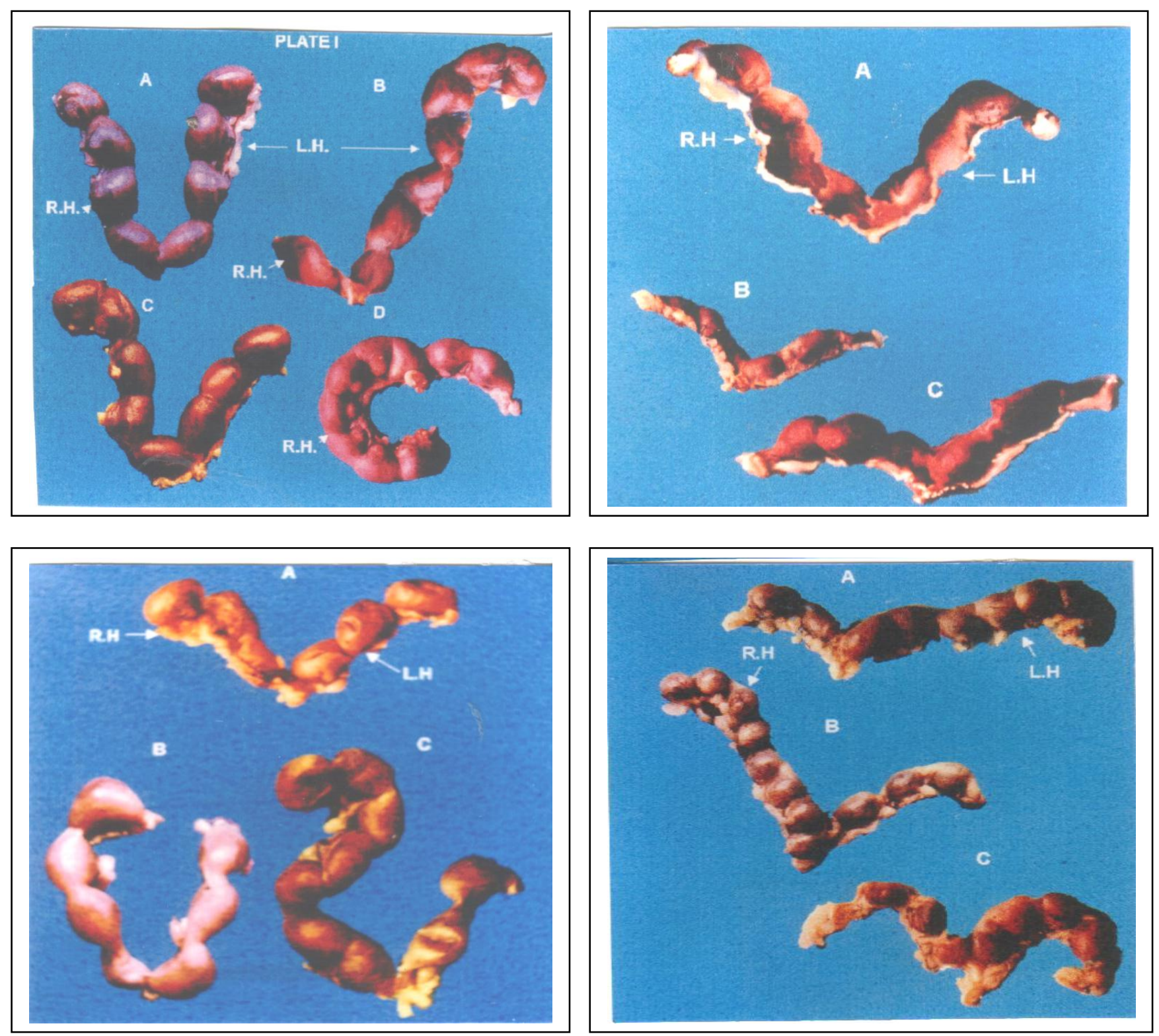

Plate I: A photograph of isolated uteri of four pregnant female rats of day 18 of gestation, (A) normal female rat with equal distribution of embryos in both hornes, (B) Artemisia treated female rat with shortness of one horn than the other, and (C\&D) salicin treated female rat with unequal distribution of embryos in both horns.

Plate II: A photograph of three isolated uteri of day 18 of gestation, (A) for diabetic female rat, showing on site of resorption $(\mathrm{B} \& \mathrm{C})$ female rat treated with gliclazide showing resorbed fetuses.

Plate III: A photograph of isolated uteri of three pregnant female rats on day 15 of gestation, (A) on normal female rat with equal distribution of embryos in both horns, (B) diabetic female rat with one site of resorption, and (C) Artemisia treatd female rat showing shortness of one horn than the other .

Plate IV: A photograph of isolated uteri of three pregnant female rats on day 15 of gestation, (A\&B) salicin treated female rat showing shortness of one horn than the other, and (C) gliclazide treated female rat with resorbed fetuses. 

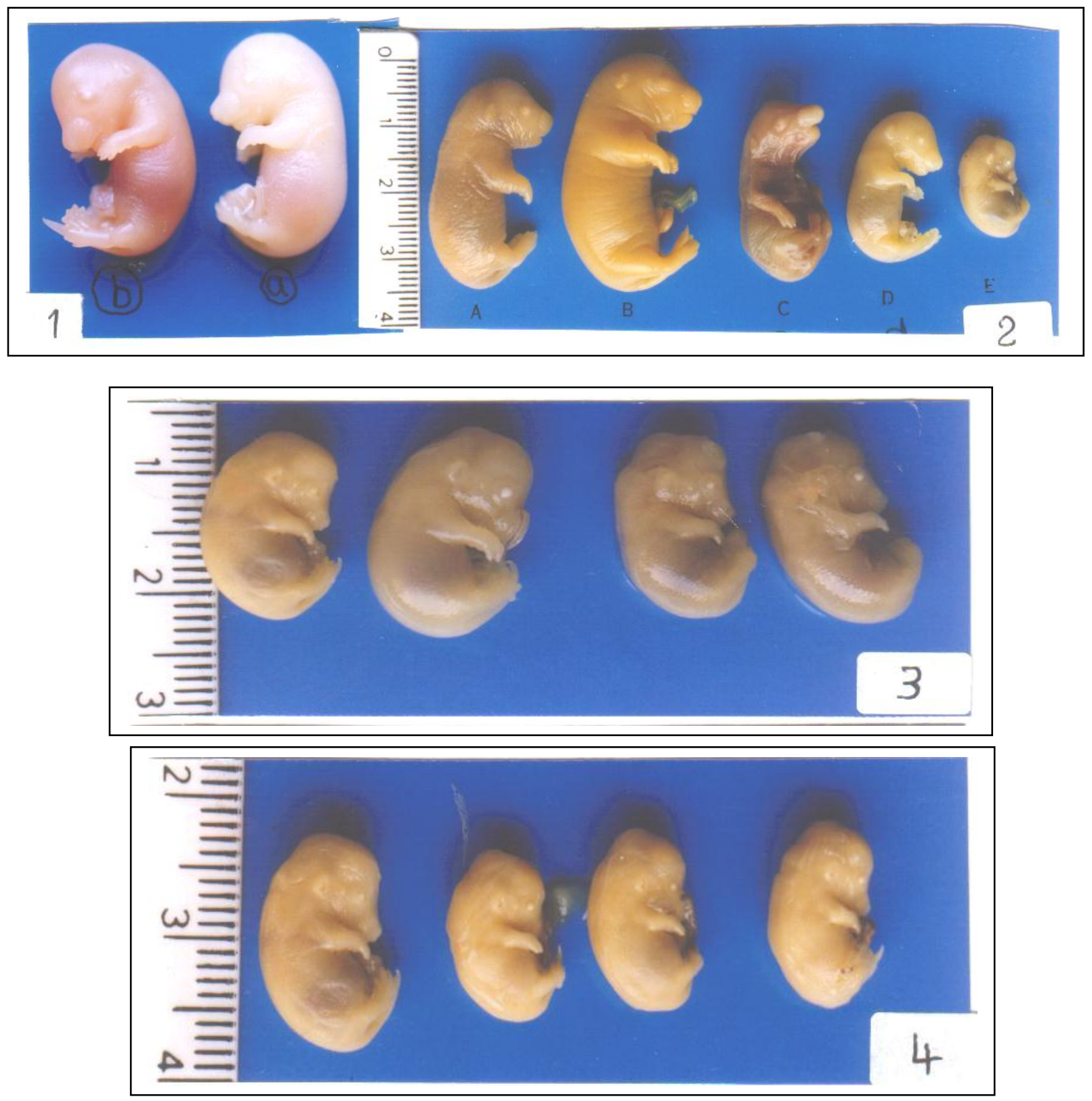

Photo(1) : Fetuses of diabetic females on day 15 of gestation.

Photo(2) : Fetuses of five pregnant female rats on day 18 of gestation, (A) normal fetus (B) diabetic mother fetus (C) Artemisia treated mother fetus (D) Salicin treated mother fetus $(E)$ gliclazide treated mother fetus.

Photo(3) : Fetuses taken from diabetic mother on day 15 of gestation treated with Salicin .

Photo(4) :Three malformed fetuses taken from pregnant rats on day 15. Theywere treated with gliclazide. 


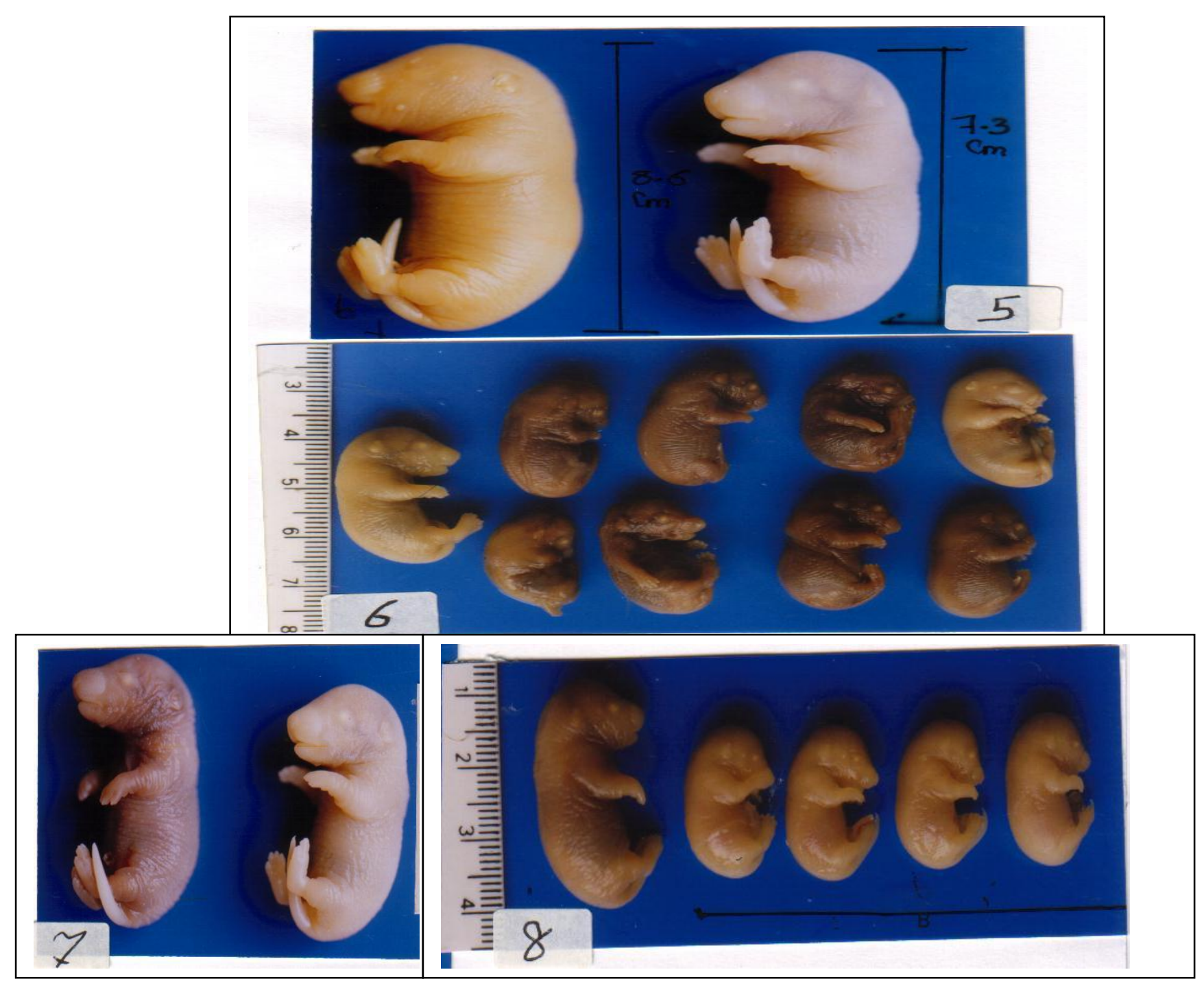

Photo(5) : (b) Malformed fetus obtained from diabetic pregnant female rat on day 18.

Photo(6) : Fetuses taken from pregnant rats onday 18 treated with Artemisia.

Photo(7) : Malformed fetuses taken from mother treated with Artemisia on day 18 of gestation.

Photo(8) :Diabetic rats fetuses treated with Salicin on day 18 of gestation. 

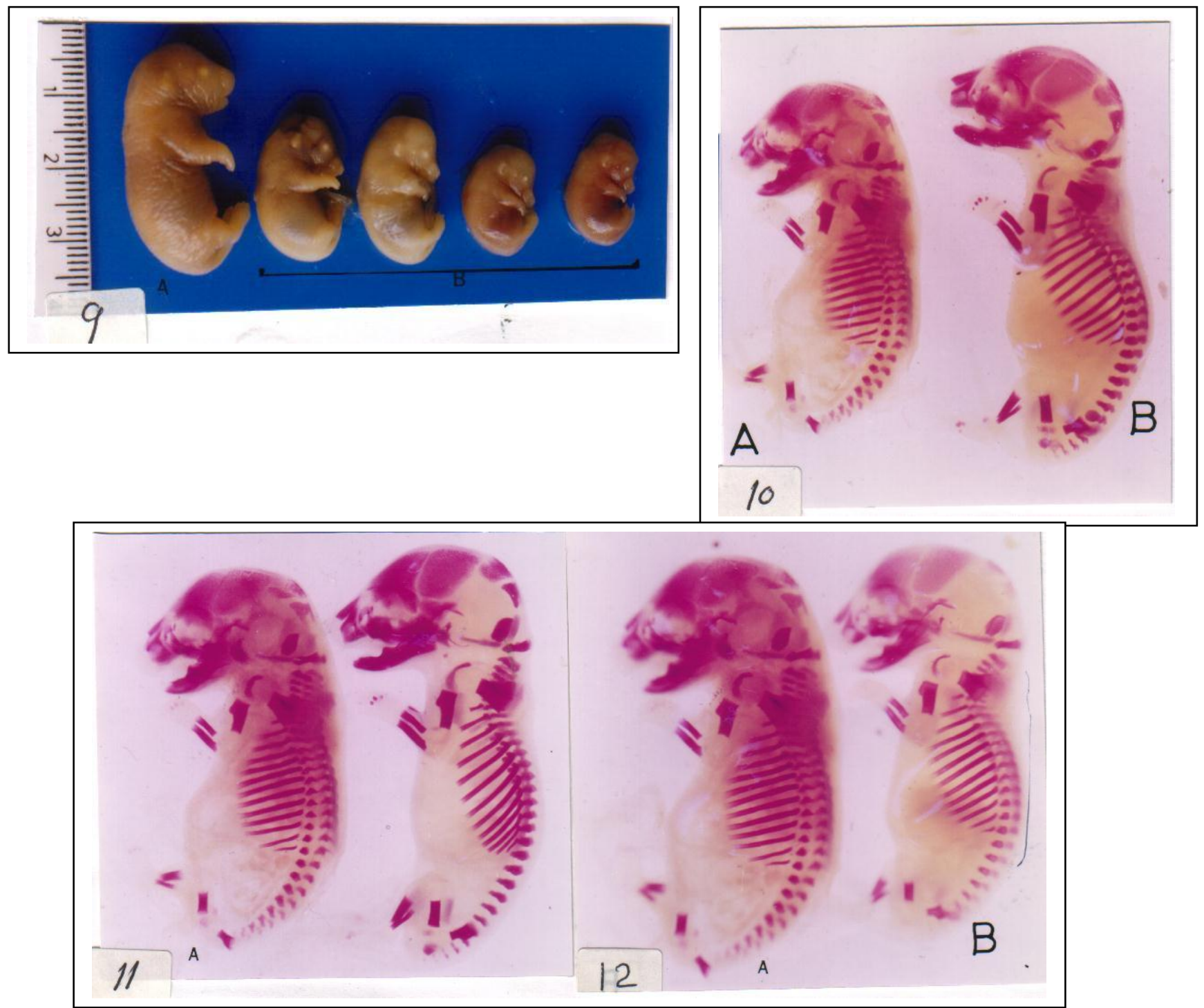

Photo(9) : Malformed fetuses on day 18 belonging to diabetic female rats treated with gliclazide.

Photo(10) : (A) Lateral view of control fetus skeleton on day 18 of gestation.

(B) Diabetic fetus skeleton (Alizarin red X4.5)

Photo(11) : (A) Skeleton of normal fetus (B) Skeleton of fetus on day 18 of gestation obtained from diobetic female rat treated with Artemisia (Alizarin red X4.5).

Photo(12) : Lateral view of fetus skeleton on day 18 of gesteation obtained form diabetic pregnant rat treated with Artemisia. 

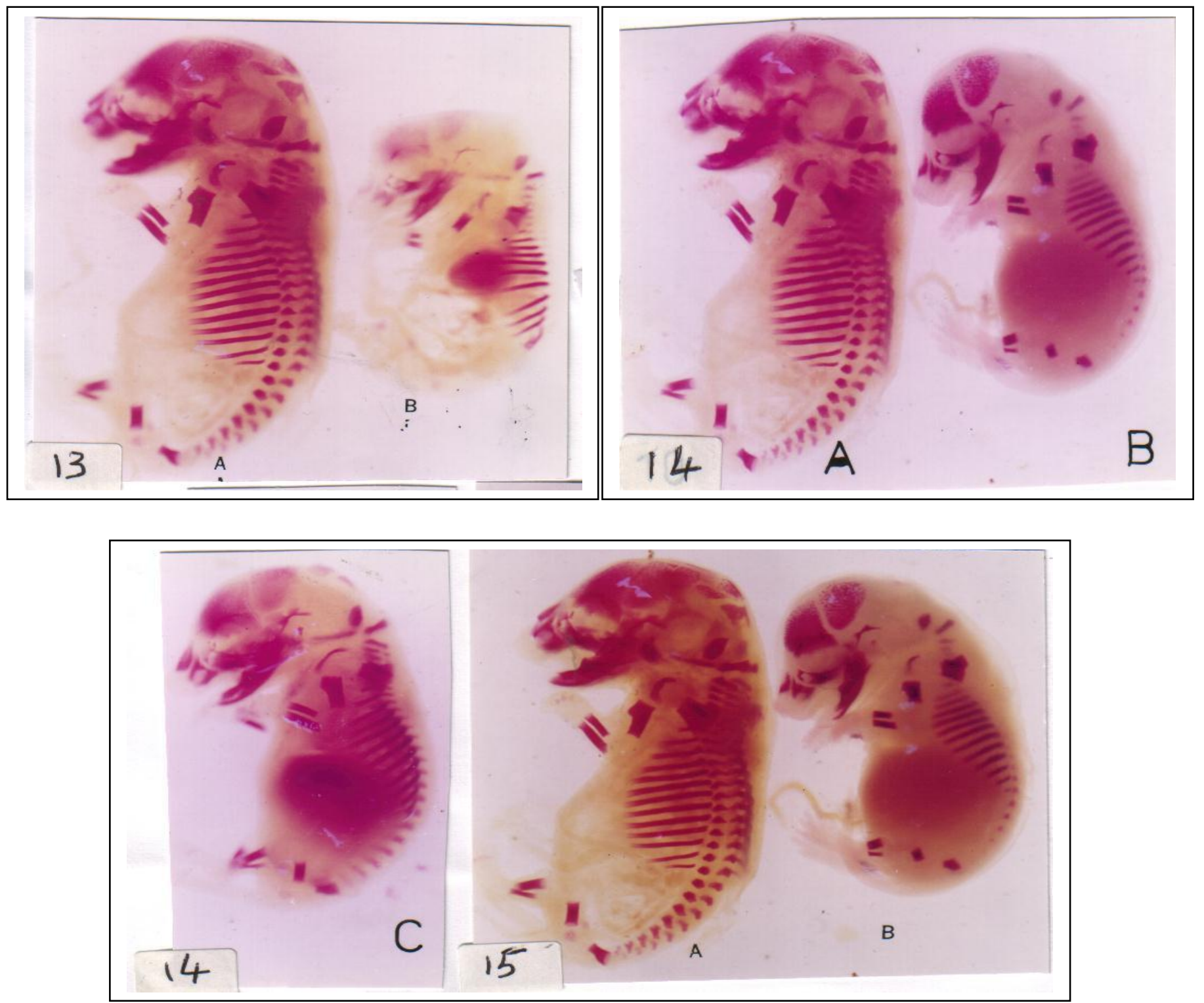

Photo(13) : (A) Skeleton of normal fetus.

( B) Lateral view of fetus skeleton on day 18 of gestation obtained form diabetic female rat treated with Artemisia. (Alizarin red X4.5)

Photo(14) : (A) Skeleton of normal fetus. (B) Skeleton of fetus maternally treated with gliclazide on day 18 of gestation $(C)$ Skeleton of fetus from diabetic pregnant female treated with salicin on day 18 of gestation (Alizarin red X4.5).

Photo(15) : (A) Normal fetus Skeleton. (B) Skeleton of fetus taken from diabetic mother treated with glicazide (18 days) (Alizarin red X4.5). 


\section{Discussion}

In the present study fetuses were taken from diabetic mothers on days 15 \&18 of gestation Mothers were treated with gliclazide (diamicron) or herbal extracts which has a hypoglycemic effect more or less similar to hypoglycemic drugs.

\section{Morphological study:}

1. Body weights of the diabetic mothers and their embryos:

The body weights of diabetic pregnant female rats and their embryos were significantly increased in this study in relation to control, this agree.

With Moss and Nulhol (1951), they reported that fetal macrosmia has been observed in diabetic pregnant mothers in human and in animal model system. Also, El-Gendy (1989), noticed that the body weight of fetuses taken from mildly diabetic mothers was significantly greater than the body weight of normal fetuses

The maternal and foetal body weights which were treated with Artemisia increased while salicin treated diabetic mothers and their embryos showed a significant decrease compared with control. This results are in agreement with to Khera (1991), who stated that ethylene glycol, sodium salicylate in pregnant rats caused a decrease in fetal and maternal body weights also Randall et al; (1991). studied the teratogenic action of alcohol, which decreased fetal weight and increased number of fetuses. The body weight of gliclazide treated diabetic mothers and their fetuses showed a significant decrease in their body weights.

\section{Percentage of resorption:}

The percent of resorption of embryos in the present study was high in diabetic mothers. This result agreed with those of Eriksson et al; (1982)., they reported that although the implantation sites per pregnant mother as numerous in the manifested diabetic group as in the normal group, the frequency of resorption was much higher.
Also El- Gendy (1989), noticed very high percentage of resorption in diabetic mothers. while the percentage of resorption in diabetic mothers treated with gliclazide showed a highly significant increase this finding in agreement with Towner (1995).

\section{Number of embryos:}

The result of the present work showed highly significant increase in the number of embryos in Artemisia and salicin treated diabetic mothers than the control but the distribution of fetuses in the two horns was unequal compared with that of the control group. This result is similar to Randall et al (1991)., they noticed decreased fetal weight with increased number of fetuses due to treatment with aspirin and alcohol; they also noticed a significant decrease in number of embryos in alloxan and gliclazide treated groups .

According to Andrus et al; (1993), treatment of mice and rat with methanal affects body weight while jaschko et al; (1993), noticed that salysilic acid in rats caused decrease in fetal length related to the high incidence of resorption. The previous result denoting that embryos were susceptible to the effect of gliclazide and diabetes before implantation.

\section{Body length of fetuses:}

The observed increased growth in fetuses belonged to diabetic and Artemisia groups were found to include not only total body weight sbut also the crown rump lengths of these sembryos.

The growth of fetuses of salicin and glicazide treated groups was found to alter not only total body weight but also crown rump lengths of these embryos. According to Andrews et al; (1993)., treatment of mice with methanol, affects body length while Joschbo (1993), noticed that salicylic acid in rats caused a decrease in fetal length.

It can be suggested that, abnormalities of growth retardation and resorbed embryos in the present investigation were probably 
caused by the direct toxicity of gliclazide on fetuses and partially by placental disfunction .

\section{The malformations :}

Malformations of fetuses, constituted a major part of the present work. Fetuses of diabetic group showed macrosomia with skin folded Hill (1987) and Macfarlane (1986) showed that fetal hyperinsulinemia has been implicated as the causative factor in the overgrowth of the fetus. Also Gabbe (1978), stated that fetal hyperglycemia and hyperinsulinism contribute to increase triglyceride synthesis in fetal adipose cells and increased deposition of subcutaneous fats.

\section{The skeletal system :}

The present study showed that fetuses belong to diabetic mothers showed normal ossification in all fetuses with enlarged skeleton however, Bourbon et al; (1985), recorded that fetuses of sub-diabetic and mildly diabetic rats were significantly enlarged in length as compared with control fetuses. Eriksson et al., (1982), suggested a pronounced retardation of skeletal development in the manifested diabetic animals, in which only half the number of calcified ossification centers was found in comparison to the normal group.

Some fetuses belonged to Artemisia treated group showed some skull anomalies, including non-ossification centers of several skull bones being including maxilla, nasal, parietal, interparietal, supraoccipital and basioccipital. Also some bones were seen with incomplete non-ossification or lack of ossification of other bones. The data were agreed with. Marin-Padilla (1966)., who stated that the deficient growth of the base of the skull especially that of the basiocciptial, has been considered to be caused by primary mesodermal insufficiency; which in itself may be the cause of a variety of developmental abnormalities involving the various axial structure.

Salicin treated group fetuses showed lack ossification of the parietal, occipital and basioccipital bones. A similar finding was reported in rat embryos by Khera
(1991) from mothers treated with sodium salicylate.

Gliclazide treated group fetuses showed diminution in size, excencephally and less ossification of parietal. MarinPadilla (1966), stated that mesodermal insufficiency would affect the normal process of formation and progressive elevation of the neural folds, which could result in their complete exencephaly failure of closure.

In the present investigation, additional defects were observed in the pelvic girdle hind limbs in some fetuses in Artemisia treated group, including lack of ossification in some parts and non-ossification in others.

It may be suggest that malformations may be attributed to the decreased absorption rate of calcium or injuries induced in the liver. Our findings suggest that the delayed or decreased ossification may be due to the interaction between Artimisia, Salicin and gliclazide and the defect in liver and Kidney tissues component during the ossification process. Khera (1991), found that sodium salicylate caused fetal abnormalities in vertebrae, ribs and sternal defects.

\section{Conclusion}

The present study revealed the adverse effect of Artemisia herba alba and salicin (hypoglycemic plants), which are similar to the effect of hypoglycemic drug (Glicozide). So traditional hypoglycemic plants must be prepared by specialist in phytochemistry and tested against animals by biologist to indicate the right close and the adverse effect, which may be caused by these plants.

Caution should be taken by pregnant women suffering from diabetes mellitus in using hypoglycemic plants;

\section{References}

1. Abdel-Moneim, A. (1998): Effect of some medicinal plants and gliclazide on insulin release in vitro. J. Egypt. Ger. Zool., 25 (A) $423-445$.

2. Al- Waili, N.S. (1986): Treatment of diabetes mellitus by Artemisia herba alba extract. Clin. Exp. Pharmacol. Physiol., 13 (17) $569-573$. 
3. Andrews, I.E.; Kavlock, R.J. and Rogers, J.M. (1993): Developmental toxicity of methanol in whole embryo culture. Toxicology, 27: 81: (3) $205-215$.

4. Azzam, S.M. (1984): Phytochemical study of certain of certain plants used in Egyptian folk medicine as antidiabetic drugs Ph.D. thesis, Faculty of Pharmacy, Cairo University.

5. Bourbon, .R., Pignol, B., Marin, Rientort; M. and Tordet, C. (1985): the role of glomerular hyperfiltration in the initiation and progression of diabetic nephropthy. Acta. Endocrinol. 97 (Supp. 242) $7: 10$

6. El Fiky, M., Abd El - Aal and Abd El Megid, M. (1997): Studies on the cerates venom, induced hypoglycemia. J. Egypt. Ger. Soc. Zool. 23 (A):15 - 35.

7. El - Gendy, A.M.H. (1989): M.Sc., thesis. Fac. Sci. Al - Azhar University. The influence of royal jelly after lead toxicity in diabetes to minimize their injurious effect.

8. Eriksson V.J.; Dmhlstrom, E.K; sunelarsson and Hellerstrom, C. (1982): increased incidence of congenital malformations in the offspring of diabetic rat. Diabetes, 30: $1-6$.

9. Gabbe, M.D. (1978): Clinical obstetrics and gynecology 21 (2) harper \& Row.

10. Ganda, O.M.P and Weir, G.C. (1990): Oral hypoglycemic agents, in principles and practical of endocrinology and methoblism. Becker, K.L. (ed) J.B. lippincot, V. SA, pp 1099 - 1101.

11. Goodman. L.S. and Gilman, A. (1980): Insulin and oral hypoglycemic drugs The pharmacological basis of therapeutics Sixth Edition pp. 1053.

12. Hill, D.E. (1987): Effect of insulin on fetal growth semin, perinatal: 2, $319-328$.

13. Hin and Wetherill (1975): The T. Test and $\mathrm{X}^{2}$ godness of lit chapman and Hall (1955) Longman, J. Nutr., 285.

14. Joschko, A., M.; Dreosit, I.E. and Tuisi, R.S. (1993): The teratogenic effects of salicylic acid on the developing nervous system in rat in vitro. Teratology - 48 (2): $105-114$.
15. Katsumata, K. and Katsumata, Y (1990): The potentiating effect of the simultaneous administration of tolbutamide and gliclazide on the development of alloxan induced diabetes in rat. Horm. Met. Res. 22 (1): $51-52$

16. Khera, K.S. (1991): Chemically induced alterations in maternal homeostasis. Their etiologic significance in rat fetal anomalies Teratol. 44: 259 - 297.

17. Mac Falane, C.M.; Tskalakos, N. (1986): The extended Pedersen hypothesis. S. Afr. J. Sci. 82 (6): 312 - 314.

18. Marin - Padilla, M. (1966): Mesodermal alterations induced by vitamin. A.J. embyo. Exp. Morph. 15: $261-269$.

19. Marles, R.T. and Farnsworth, N.R. (1995): Antidiabetic plants and their active constituents. Phyto medicine, 2: 137 - 189.

20. Moss, J.M. and Nulhol, H.B. (1951): Diabetes and pregnancy with special reference to the pediatric states. Ann. Inern. Med. 34, 678 - 691.

21. Pastte, G.E. and Sarnes, J.M. (1964): Toxicity tests. Evaluation of drug activities pharmacometrics, Vol. 1 Academic Press. London and New York.

22. Randall, C.L.; Anton, R. F.; Becker, H.C., and Ekblad, U. (1991): Aspirin does-depend - ently reduces alcohol induced birth effects. Teratol., 44 (5): 521 529.

23. Sedra, S. N. (1950): Decreasing the time required for making on a bzarin skeleton. Prep; stain, Technol. 25 (4): 223.

24. Soler N.G., walsh C.H. and Malins J.M. (1976): Congenital malformations in infants of diabetic mothers. Med. 45 (178): $303-313$.

25. Temesio, and poses, V. (1977): Congenital malformations in diabetic offspring. Acta Diabetol. 14 (5-6): 192 - 198.

26. Towner D; Kjos, S.L.; Leung, B., Montora, M.M., xiang, A. and Buchanan T.A. (1995): Congenital malformations in pregnancies complicated by NIDDM Diabetes care, 18 (1): 1446 - 1451. 


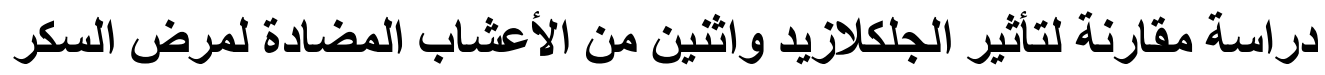

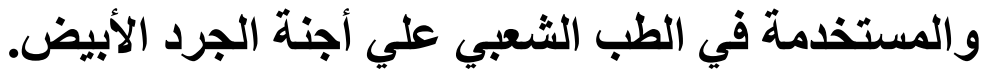

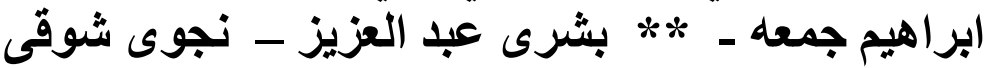

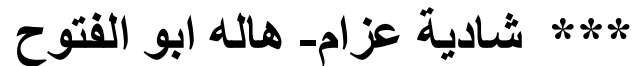

كلية علوم جامعة الأزهر * بنين ** بنات *ثم هاله ابو كلية الصيدلة جامعة القاهرة

صمدت هذه الدر اسة لمعرفة التأثير ات الظاهرية التي يحدثها الجليكلازيد (دياميكرون)

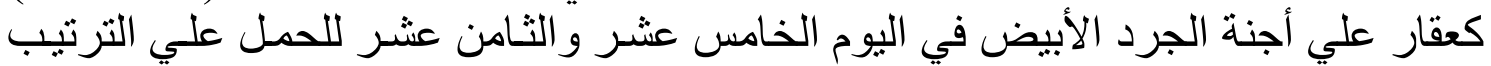

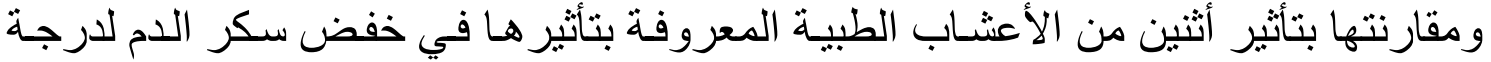

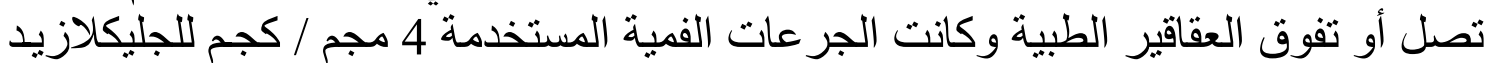

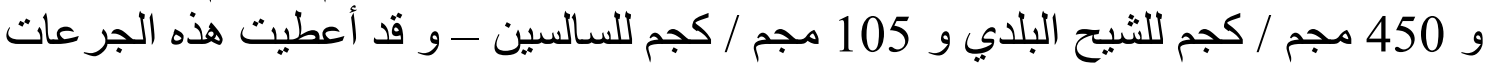

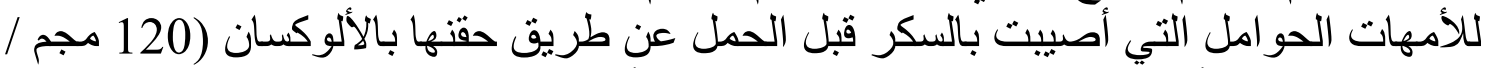

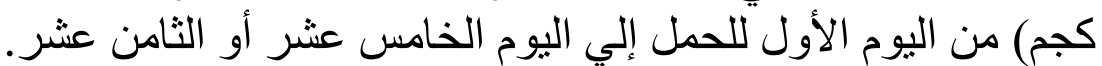

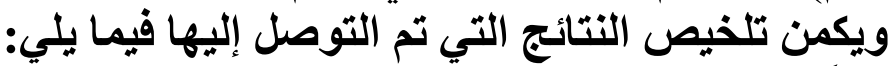
أولاً: الاراسة الظاهرية التانية

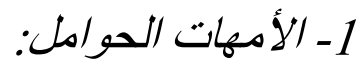

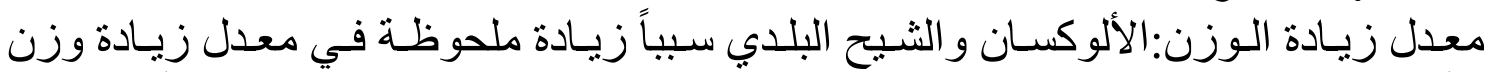

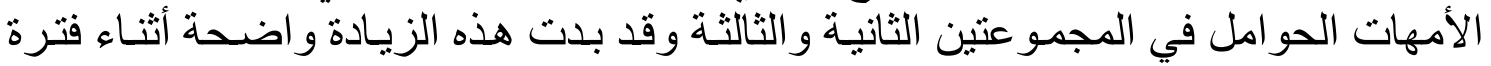

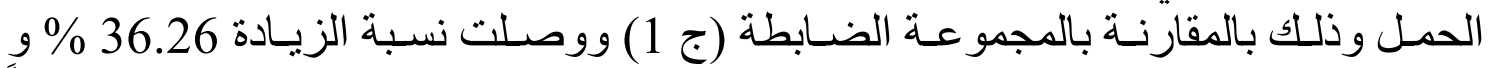

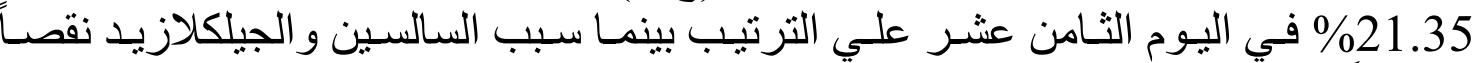

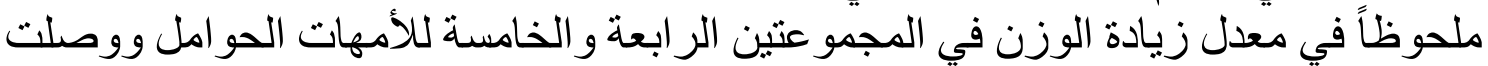
نسبة النقص في 11.19\% و 6.06\% في اليوم الثنامن عشر علي الترنيب.

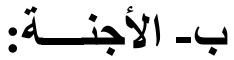
1- عدد الأجنة:أظهرت الدر اسة أن السالسين والثيح البلدي سبباً توزيعاً غير متسـاوى في

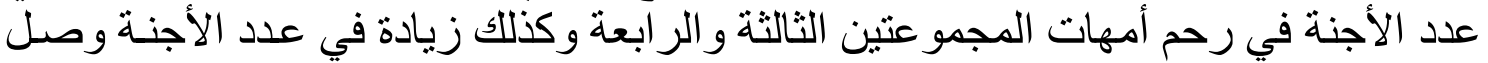

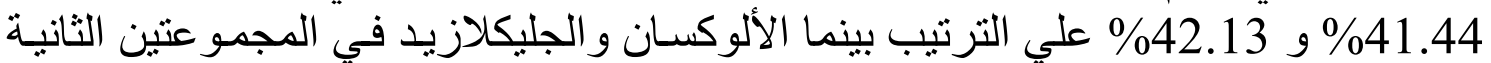

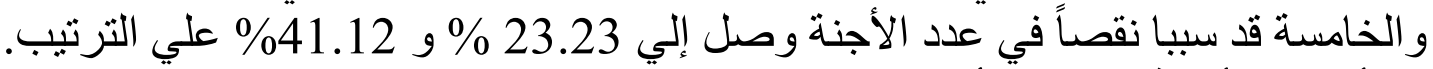

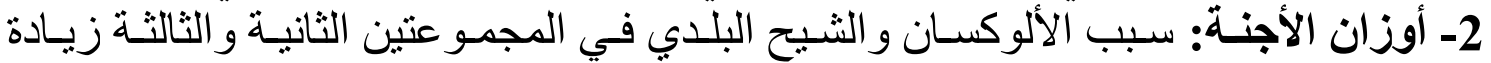

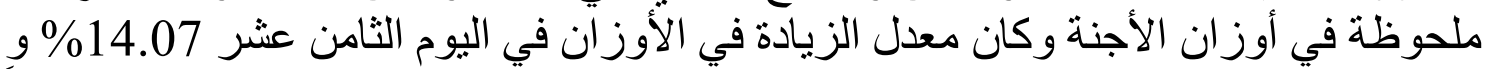

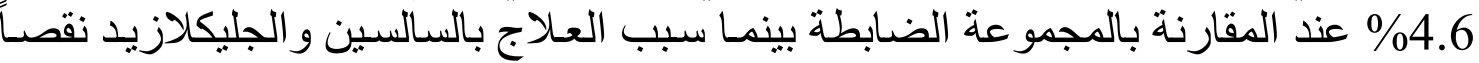

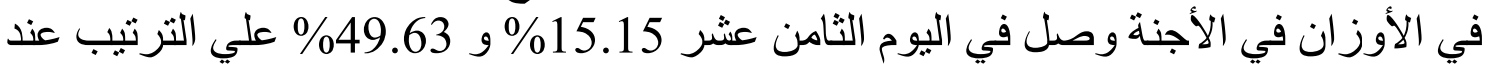

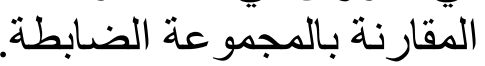

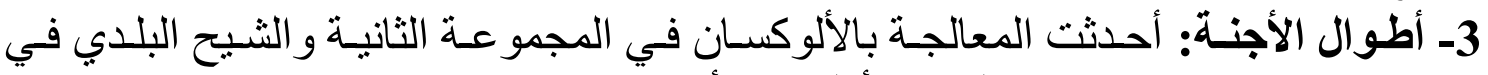

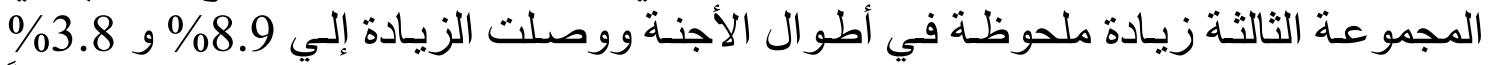

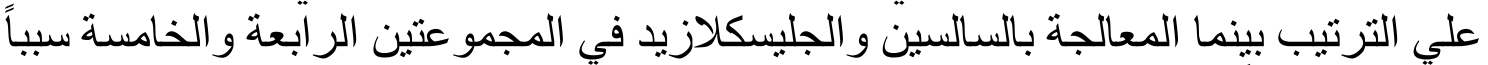

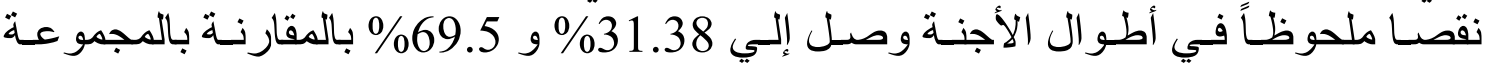
الضابطة. 


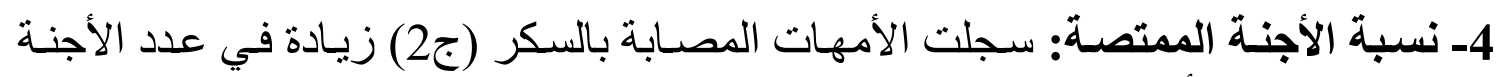

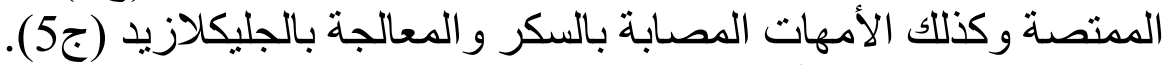

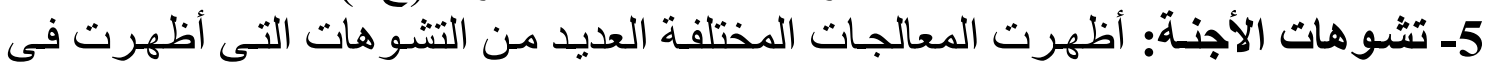

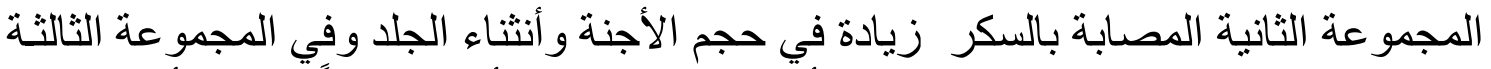

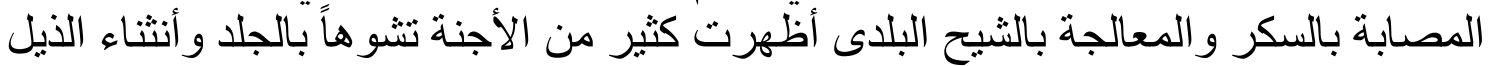

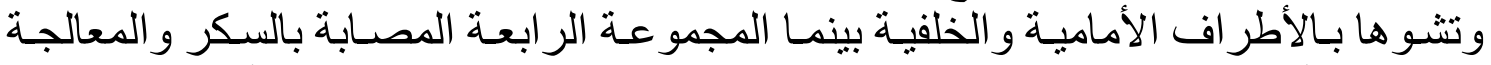

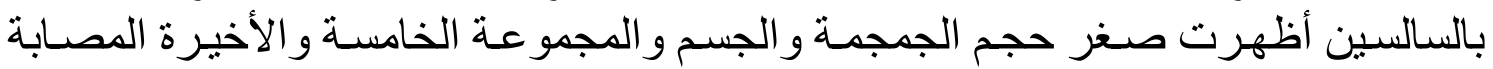

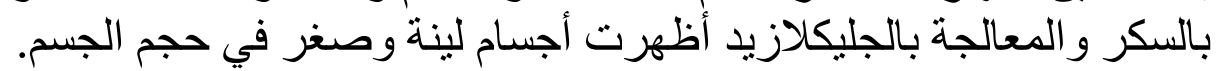

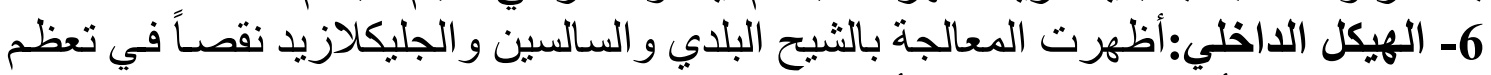

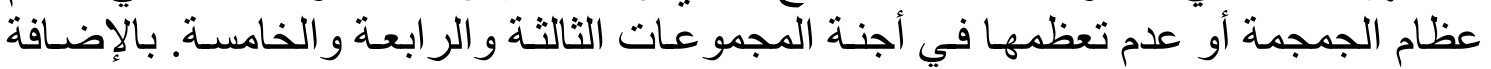

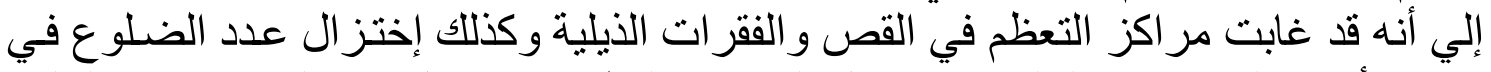

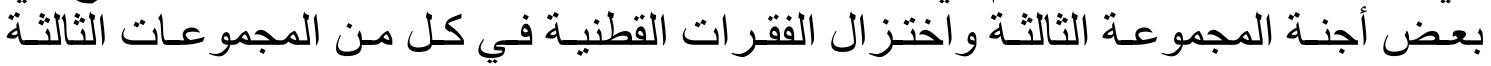

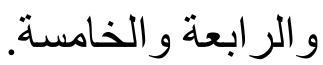

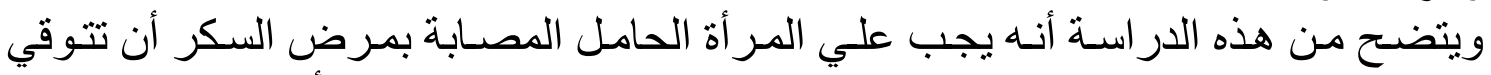

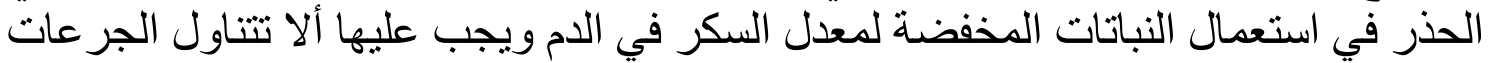

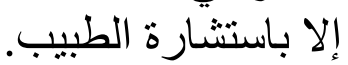

